\title{
IMPACT OF ENVIRONMENT CONGRUENCY ON ORGANIZATIONAL PERFORMANCE: THE MEDIATING EFFECT OF CULTURE AND STRATEGY
}

\author{
Nancy Haidar Ismail
}

Beirut Arab University, Beirut, Lebanon

This research has been aimed at evaluating the effect on the performance of workers of the Finance Management Institute. Descriptive research approach has been utilized for this. Simple random sampling technique was used to select the respondents for this study. The sample consisted of 25 senior employees and 25 younger employees (thus 50 in total). For data gathering, structured questionnaires have been utilized. The results of the research show that workplace organization has an effect on the respondents. The study has also shown that if management addresses the issues that have been discovered throughout research, the workers would enhance their performance. Such problems include flexibility in the workplace, noise distractions, personal connection of supervisors with workers, the availability of job support, the use of feedback for promotion and incentives. The results of our research also indicated that in order to resolve employee complaints, the company must have regular meetings with its workers as part of the motivating element. Management should develop methods and means of informing its workers of its objectives and plans so as to accomplish its mission, vision and business.

Keywords: organizational performance, organizational environment, company strategy, company's culture, vision and mission, employer-employee relations

\section{Introduction}

In this paper, we will try to determine what is optimal performance that should be followed by any organization in order to achieve congruence between its resources, structure and processes from one side and the environment from the other side so that to accomplish sustainability.

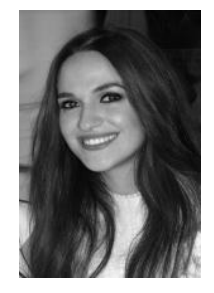

\footnotetext{
Nancy Haidar Ismail

Master in Engineering Management (American University of Beirut), Doctorate Student in Business Administration, Beirut Arab University, Lebanon. Research interest: engineering; management; leadership; marketing.

Email: nancyismaiil@hotmail.com
} 
The importance of the congruence model to be applied within any organization will be highlighted. This model shows how any company transforms its inputs such as resources into outputs such as goods and services, by using various elements, and these elements should be congruent together in order to achieve stability. Then, after the analysis which determines that these elements do relate to each other, we can then build and sustain congruence if it is present, or resolve the incompatibilities and try our best to close the gaps identified if the elements are incongruent. After analyzing the congruence of the elements in the model, we should then proceed further to understand the contingency approach that is a must if we need to master the analysis of the organizational environment, strategy, technology, employee motivation, organization's structure and managerial style (Bao et al., 2019).

The emphasis here is on the congruence of values between employees and the organization since it has a positive impact to both these entities, leading to higher organizational efficiency and effectiveness which in turn will lead to more successful performance of the organization overall. In other words, our personal and professional lives have to be congruent in order to achieve the sustainability at both work and life which is essential for both human and social development.

Edwards \& Cable (2009) stated that leaders and managers today are facing perhaps the biggest challenge in the history of mankind, as they are striving with how to create and maintain successful organizations based on what is equally good for business, people and society at the same time.

\section{Theoretical background}

The Nadler-Tushman congruence model was first introduced in the early 1980s by the theorists David A. Nadler and Michael L. Tushman in order to identify the root causes of performance issues at any organization and to determine in what ways to analyse them. That is to say, to identify the performance gaps that have to be resolved in order to increase organisation's productivity and profitability. This model consists of an open system which has three main sections - inputs, the transformation process and outputs.

The inputs of this congruence model are the strategy, the environment, the resources and the history.

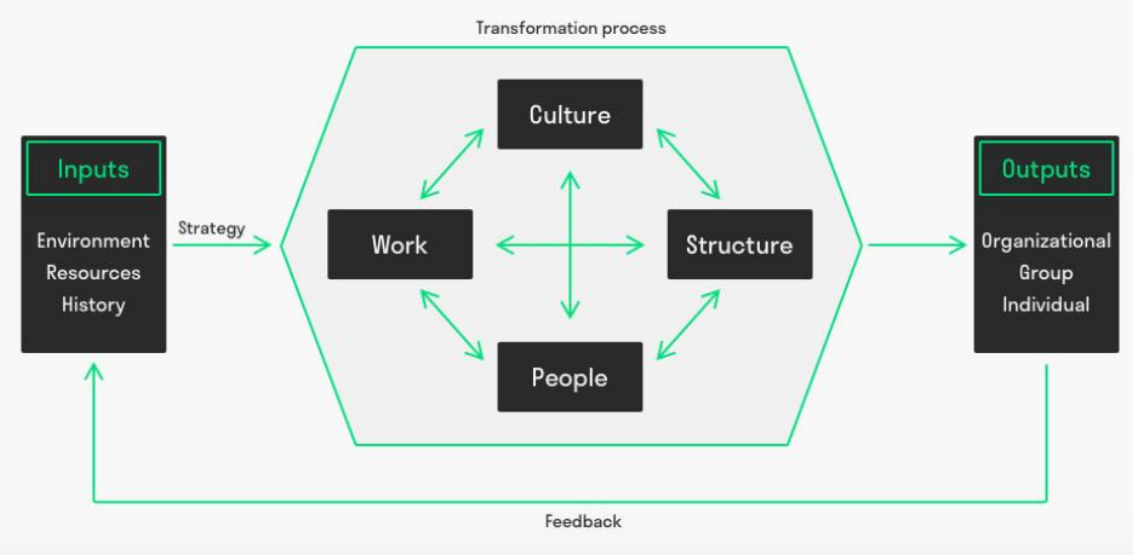

Figure 1 - The Nadler-Tushman congruence model 


\section{IMPACT OF ENVIRONMENT CONGRUENCY ON}

The strategy is a crucial part of the input, it is defined by the ability of the organization to meet its demands by taking critical decisions using available resources, considering the environment's needs in addition to the historical experiences associated with the organization that is trying to reach the desired goal. An important question to consider here: Is the vision of the organization clear and understandable for all of its employees?

The environment in this case includes all the institutions, groups, individuals and events that are outside the organization, but might have a potential impact on it.

The resources are represented by the assets of the organization such as human resources, information, capital and most importantly, reputation of the company defined by its intangible resources (Sabir, 2018).

Then, the history is represented by the past behaviours practiced by employees, in addition to company's policies, activities and the recruitments done for the organization that may affect present and future operations (for example, when the company aims to recruit staff with technical experience without giving importance to university degrees or vice versa).

This model (see Fig. 1) has four main elements - the work done, the people performing it, the organizational structure and the organization's culture. When these elements are congruent together, the organization is successful, however, when there is an incongruence or one of the elements does not fit or is not related to the other, then a problem might occur within the organization. Thus, these elements must be analyzed in order to identify congruence/incongruence. Success can only be guaranteed if the elements of the congruence model are in harmony with each other (Brandstatter et al., 2016).

With respect to work, the task given to each individual working for the organization should be clear and comprehensive. In other words, a clear job description should be allocated to each employee. The focus should be made on the work done and how it is processed.

With regards to the employees and other people working for the organization, the expertise, skills and knowledge for each member working should be recognizable, identified and awarded if the tasks are well accomplished. Since more than $70 \%$ of our time is usually spent at work, recognition and awarding are a must in order to keep the positive spirit and involvement (Veinhardt et al., 2016). It is then easily identified whether the members are committed to the organization and what career evolution expectations they have. The value congruence of employees and the organization is positively related to job satisfaction, motivations and awards, decision-making delegation and organizational commitment. Employees who feel that their work environment is supportive, tend to engage more readily in creative ways of solving the problems they might encounter at work.

P-E fit, or personal-environment fit is the compatibility that occurs when an individual and work environment characteristics are well matched.

Successful organization adaptability is a function of an organization's key members' making adjustments that match changes in the external environments (Randolph et al., 1984).

Concerning the organizational structure, it is analysed by pinpointing rules, policies, procedures and measures related to the organization. For instance, a bureaucratic culture at an organization usually has the slowest decision-making procedures but at the same time the latest technologies, and this might lead to complications and problems within the organization. 
As regards to Culture, this element has the greatest influence as it is related to people's attitudes, beliefs, values and behavior. The organization's culture can be analyzed by considering the beliefs of the individuals working inside it. Thus, we can affirm that each organization is unique as each one has its own culture from the staff recruited and their attitudes (Mor \& Henson, 1996).

After analyzing the transformation process of the model, we get the outputs defined on organizational, group and individual levels.

Now we need to analyze how the elements of the congruence model are interrelated.

Firstly, regarding work and people, we should be able to analyze if the work needed to be accomplished, is done by a skilful person, and on the other side, whether the person performing the work is satisfied and has all their needs fulfilled. This Person-Job fit is one of the most important features to analyze. The organization must be able to recognize the most important aspects that the employees are looking forward to have. These values can be summarized and grouped as: economic, social, spiritual, moral, professional, aesthetic, and physical values.

In order to get positive outcomes, trust and communication between employees and the organization are vital to be ensured. These aspects will contribute to job satisfaction and organizational identification. Then employees will be more productive, and they will feel like they belong, thus they will be more committed to the organization, more productive, and more likely to engage in extra-role behaviours. The congruence of personal and organizational values happens when the values of both parties align together, when the congruence exists, the employee's attitudes towards work will be positive which will yield to the organization's success in the present and the future (Spanjol \& Tam, 2015).

At a time when company's ethics and accountability continue to affect organizations, it is important for managers to understand the values held by their employees.

Concerning work and structure, we should assess whether the work is done in a wellorganized manner and whether the structure is sufficient to meet the demand of the work accomplished.

Regarding the structure and the people, we should examine whether the structure allows employees to work together successfully, and whether people perceive this structure as a clear or an uncertain one.

As regards to people and culture, we should be able to determine whether the culture of an organization is in accord with the people working at that organization and whether this culture makes use of people's resources (Morgan, 1986).

With reference to culture and work, we should check whether it assists or delays work performance. Eventually, regarding the structure and culture, we must determine whether culture and structure complement one another or the opposite - whether they compete together.

These assessments of the elements in pairs will give us an idea about the congruences and incongruences that exist inside the organization and in what ways we can enhance the performance and achieve goals by strengthening or sustaining the elements that are already well coordinated and congruent, and/or try fix the elements that are incongruent.

It is important to consider that each organization is unique as we cannot take the procedures done for one organization and apply them automatically to another one, since each organization has its own structure, culture, people with different beliefs and behaviours and work criteria that might be totally uncommon to another organization. It is also crucial to 


\section{IMPACT OF ENVIRONMENT CONGRUENCY ON}

mention that a marketing targeted organization could focus on assessing the so-called 4Ps (product, price, promotion and place) by analyzing the congruence between them instead of focusing on the work, people, structure and culture already discussed in the Nadler-Tushman model. Another approach is the analysis of the McKinsey 7-S framework which focuses on the congruence between Strategy, Structure, Systems, Style/Culture, Staff, Skills, and Shared Values (Esposito \& Williams, 2010).

Contingency theory is significantly important to organizational behaviour, it is defined as the adaptation of organizations to the environment, where these organizations act as open systems. This theory claims that there is no best way to organize a company and make decisions, and the ideal way to make decisions as such is by relying on internal and external constraints, which are defined by the size of an organization, its adaptation to the environment, its resources and operations, different strategies and technologies used.

\section{Methodology}

This research aims at staff managers who are accountable for the performance management of their workers and their employees. Due to the geography factor, the Institute of Finance Management has been chosen. This research thus aims to provide more relevant information to help managers overcome various obstacles and improve the performance of workers by enhancing the quality of their working environment.

\section{Population of the Study}

A population is any group of people that has one or more common traits and are of scientific interest for a researcher. The target group in our research is thus comprised personnel officials, department heads, managers and personnel. The population of the financial management institution under study is 320, including both teaching and nonteaching personnel.

\section{Sample Size}

This research has chosen the respondents who are directly controlling the performance of workers and employees. The interviewees have assisted the leading investigator to plan the survey and then generalize the obtained results.

The sample of 50 teaching and non-teaching respondents were approached and asked to reply to a questionnaire.

The sample of 50 respondents from the total population of 320 workers was chosen because they felt that their jobs represented and included essential information for this particular research.

It would be virtually impossible to gather and then test data on every element in our research since in this case our final sample would have comprised several hundred or even thousands of components. Even though the idea of having the whole population as our sample seems to be somewhat feasible, there were also time, money and other human-related constraints which made us reject this idea from the very beginning. 
Table 1 - Population of the study

(made by the author)

\begin{tabular}{|l|c|c|}
\hline \multicolumn{1}{|c|}{ Participants } & Target Population Size & Sample Size \\
\hline Human Resource Officers & 4 & 4 \\
\hline Heads of Departments & 40 & 10 \\
\hline Directors & 15 & 5 \\
\hline Staff Members & 261 & 31 \\
\hline Total & 320 & 50 \\
\hline
\end{tabular}

\section{Data collection tools}

For the collection of accurate and trustworthy enough data, having a single method or instrument cannot be regarded as sufficient. Two main tools for obtaining sufficient and trustworthy information have thus been utilized. These were organized and semi-structured interviews and surveys. Data collecting methods included observations, interviews and questionnaires.

\section{Questionnaire}

Using a series of questions has been our primary data collection technique. The selected respondents had to answer questions by themselves, independently, and then returned their answers to the researcher.

\section{Observation}

The observation technique as such enables the researcher to watch how interviewees are performing their daily tasks and how they overall function in their usual work environment.

This research has utilized the technique of observation to evaluate the working environment of the employees and to assess the availability of resources needed for the organization's work performance. The observation has, inter alia, enabled us to get nonverbal answers. The checklist was used to accomplish this.

\section{Interviews}

The data-gathering technique of an interview usually includes some sort of an oral stimuli which provokes oral or verbal answers. This procedure is normally utilized in the course of a personal interview or as a telephone interview if feasible.

This study has utilized personal interviews. Face-to-face interviewing has been chosen because this method allows getting valuable additional information while gathering data. In our case, the interviews included open questions, and the respondents were encouraged to address the topics of interest in fullest detail.

\section{Reliability and Validity of Data}

Measures were then applied to justify the validity of this research data obtained. Using both questionnaires and interviews as the data collecting techniques guaranteed the quality of findings. Reliability is the level of consistency shown by the instrument or process. Reliability of the findings obtained from the interviewees was, of course, measured in this research. 


\section{IMPACT OF ENVIRONMENT CONGRUENCY ON}

\section{Data Analysis}

In this research the data was evaluated using percentages from the answered questionnaires. In order to demonstrate dispersion in the collected replies the data gathered was verified for consistency, then frequencies and percentages. The software utilized for all this was the Social Science Statistical Package (SPSS).

\section{Structural Equation Model}

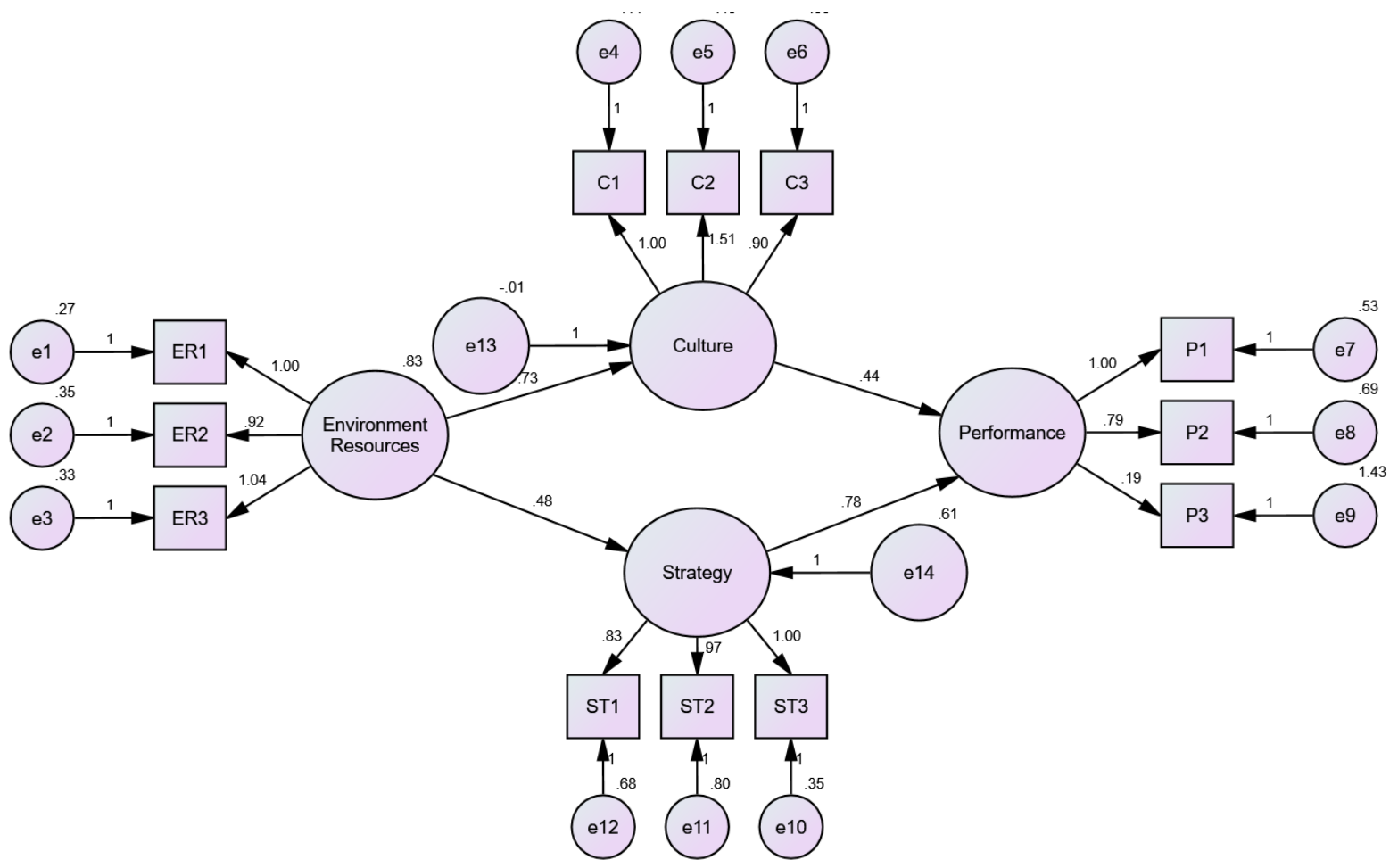

Figure 2 - Structural equation model (made by the author)

The Fig. 2 shows a structural equation model which aims to study the mediating effect of strategy and culture on the environment resources and performance. The bigger circles represent the latent variables and the smaller squares represent the constructs that are used to measure the latent variables. Finally, the smaller circles represent the standard error for each variable.

\section{Regression Weights: (Group number 1 - Default model)}

Referring to the above regression analysis, it can be noted that there is a direct relationship between the dependent and the independent variables since the significance level is below 0.05 .

Environment is significant for Culture since it scored the P-Value of 0.004.

Environment is significant for Strategy since it scored the P-Value of 0.005 .

Culture is significant for Performance since it scored the P-Value of 0.008.

Strategy is significant for Performance since it scored the P-Value of 0.036 . 
Table 2 - Regression weights

(made by the author)

\begin{tabular}{|c|c|c|c|c|c|c|c|}
\hline & & & Estimate & S.E. & C.R. & $\mathrm{P}$ & Label \\
\hline Culture & $<--$ & Environment Resources & .735 & .066 & 11.047 & .004 & \\
\hline Strategy & $<---$ & Environment Resources & .478 & .082 & 5.836 & .005 & \\
\hline Performance & $<---$ & Culture & .442 & .105 & 4.212 & .008 & \\
\hline Performance & $<---$ & Strategy & .775 & .093 & 8.298 & .036 & \\
\hline ER1 & $<---$ & Environment Resources & 1.000 & & & & \\
\hline ER2 & $<---$ & Environment Resources & .915 & .066 & 13.829 & .041 & \\
\hline ER3 & $<---$ & Environment Resources & 1.038 & .069 & 15.020 & .017 & \\
\hline $\mathrm{C} 1$ & $<--$ & Culture & 1.000 & & & & \\
\hline $\mathrm{C} 2$ & $<---$ & Culture & 1.507 & .140 & 10.749 & .014 & \\
\hline $\mathrm{C} 3$ & $<---$ & Culture & .904 & .128 & 7.053 & .003 & \\
\hline $\mathrm{P} 1$ & $<--$ & Performance & 1.000 & & & & \\
\hline $\mathrm{P} 2$ & $<---$ & Performance & .786 & .092 & 8.529 & .001 & \\
\hline $\mathrm{P} 3$ & $<--$ & Performance & .193 & .108 & 1.779 & .015 & \\
\hline ST3 & $<---$ & Strategy & 1.000 & & & & \\
\hline ST2 & $<---$ & Strategy & .969 & .104 & 9.301 & .023 & \\
\hline ST1 & $<---$ & Strategy & .830 & .093 & 8.905 & .036 & \\
\hline
\end{tabular}

\section{Analyzing the relations between the organization and the environment}

The contingency approach advises that in order for an organization to succeed and meet the challenges, there should be an internal balance related to: structure, managerial styles, and the technologies employed along with an external balance related to the environment. Any incongruence among management processes and the organization's environment tends to reduce organizational efficiency and effectiveness.

Miles and Snow suggested that any organizational strategy falls into one of four categories: Prospector, Defender, Analyzer and Reactor.

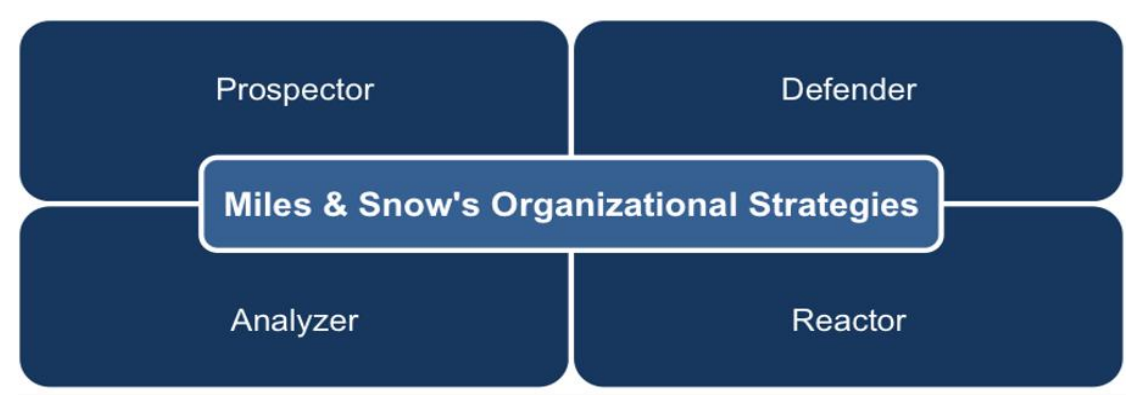

Figure 3 - Miles and Snow’s organizational strategies

(made by the author)

A prospecting organization is expected to constantly achieve innovation and development, this kind of organization does not rely on the products that already exist at the market, instead, it innovates and creates new ones. 


\section{IMPACT OF ENVIRONMENT CONGRUENCY ON}

Therefore, the strategy applied by this organization would always include innovations, development and taking risks. This kind of strategy is most suitable when the environment is unstable and turbulent.

"A prospector organization tends to see its products as relatively short-term ventures and uses technologies, organizational structures and managerial styles that create and support the required flexibility. It recognizes that it must have a capacity to keep on the move so that it can evolve along with changing opportunities" (Morgan, 1986, 76).

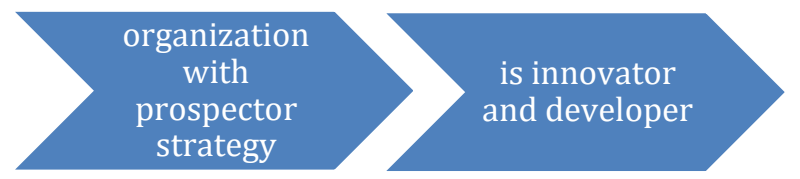

Figure 4 - Organization with a prospector strategy

(made by the author)

A defending organization is satisfied with their current occupation in the market, they do not invest in the development of new products, instead, they focus on sustaining a profitable environment where they can rely on the quality and cost effectiveness of the products that have the most affordable price to keep competitors away, so this kind of organization maintains stable growth by serving the current customers.

Some of the companies that were once innovative tend to shift gradually to become defender organizations. This happens when they cease to innovate new products. This kind of organizations usually operates within a stable environment.

Morgan $(1986,76)$ stated that defending firms usually have a very clear understanding of what they are doing, they keep defending their current position as long as the environment is stable or can be quickly stabilized so that the defender firm can stay same effective.

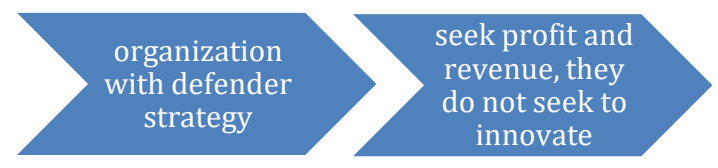

Figure 5 - Organization with a defender strategy (made by the author)

An analyzing organization is somehow a mixture between the prospector and the defender, it takes the strength of both types of organizations. Usually, this organization is large enough and faces the greatest challenge since it is able to develop innovative technologies and at the same time defend its market share with high-quality products. Therefore, it usually aims to maintain current market positions and customer satisfaction with a moderate emphasis on innovation. It might not be the first to create a brand new technology but has the capacity to spot the rising market demand and improve something created by another firm.

"The analyzer firms are very much market-driven, using R\&D and production capacities in a supporting role. They place emphasis on responding quickly and using 
technologies and organizational styles that support this. They usually have a well understood core technology that can be easily retooled and adapted to fit the needs of new product designs" (Morgan, 1986, 77).

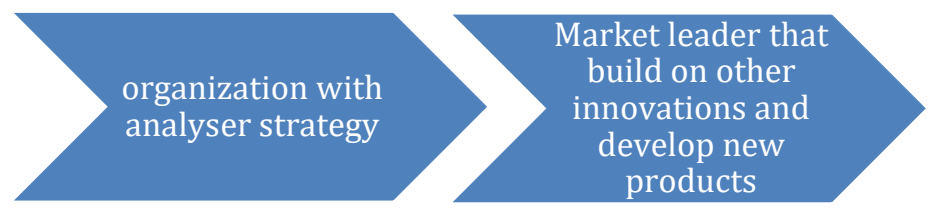

Figure 6 - Organization with the analyzer strategy (made by the author)

Finally, a reacting organization has the simplest strategy, it simply wants to catch up with the market as it doesn't fall into reactor/prospector/defender categories. Such firms/companies just react to various market alterations.

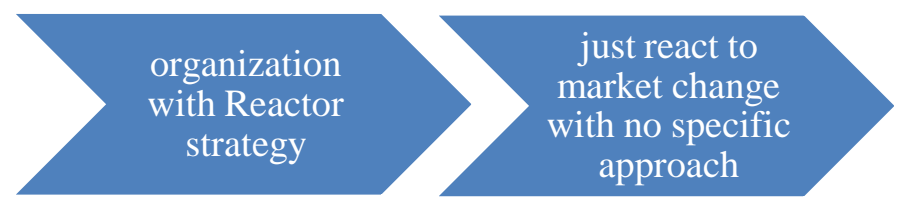

Figure 7 - Organization with the reactor strategy (made by the author)

After assessing the four categories of business strategies as presented by Miles and Snow (1978), we are able to identify what category our organization falls into. Then the structure will be clearly defined, and the goal of the organization will be achieved. For instance, an innovative company will need to employ more of creative thinkers in order to lead the market with new technologies and innovative concepts since it is a growth-oriented organization.

Defender organizations are the ones that develop relations similar to line A, while prospector organizations are illustrated by line $\mathrm{B}$, the Analyzer organization tries to achieve the middle ground as shown by line $\mathrm{C}$.

\section{The Structure of the Organization}

Summing up, we can state that the structure of the organization in question is a rigid bureaucracy where the organization is acting as a machine and all tasks to be done by employees are fixed, straightforward, precise, with well-known regulations, and detailed rules, and everything is clear, reliable, efficient and understandable as in an mechanistic organization. And if the organization's structure is organic, then there would be no clear vision or tasks given to employees, they have to rely primarily on their imagination and creativity in order to enhance profits of the company. 


\section{Profile of Organizational Characteristics}

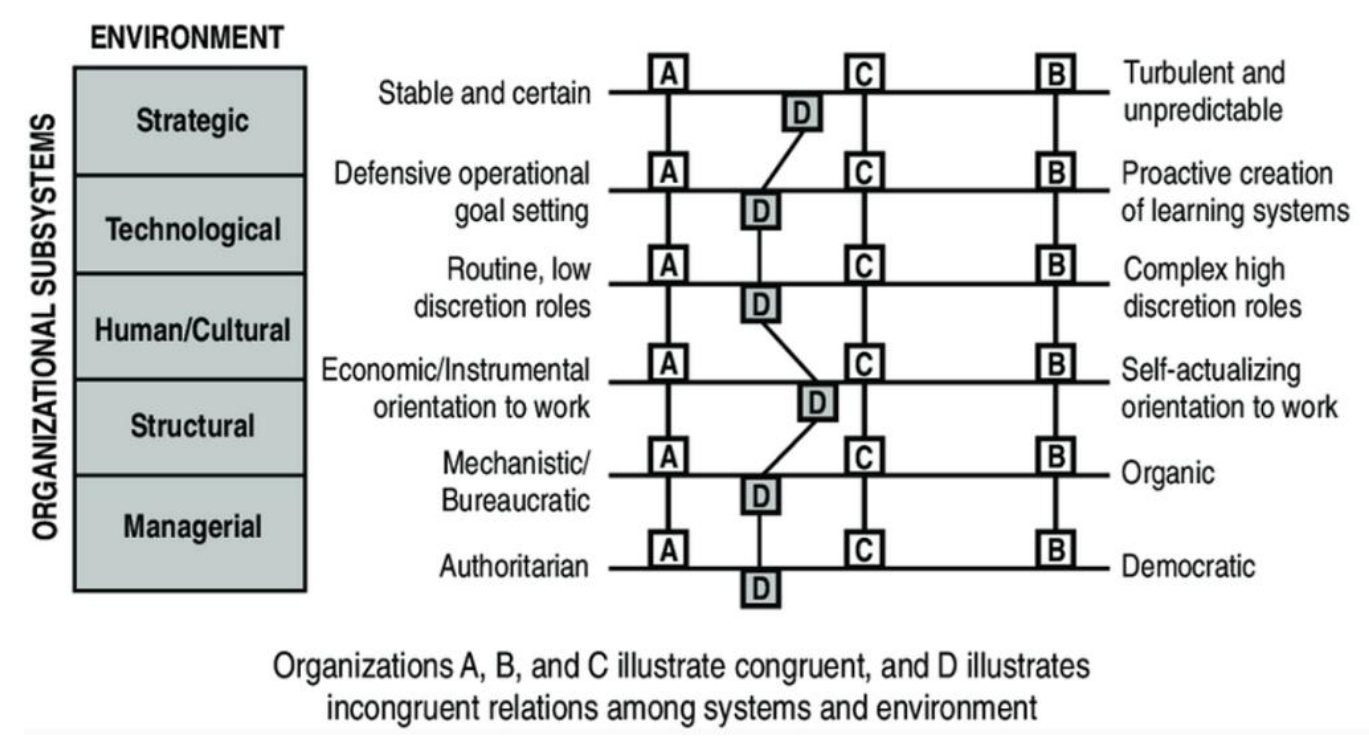

Figure 8 - Congruence and incongruence within organizations

(made by the author)

\section{Conclusions and Recommendations}

The initial concept remains true: when compatibility between the components of the congruence model is strong, the organizational performance would be high and effective. And if we do not work properly with the drivers of our performance, success would eventually be affected.

The congruence model allows us to analyze the inputs and the components and thus to determine the gaps in any organization. However, it has certain drawbacks since it does not include issues-resolving methods, does not demonstrate how to solve problems inside the company itself. The significance of the fit among the components of congruence is only highlighted. In addition, this approach does not address what is also important to understand outside the company.

The theory on contingency, described by Miles and Snow, enables us to understand further how the organization may be analyzed, whether it is prospective, analytical, defensive or reactive, by defining the very structure of the organization. It is important to consider that what prevails in one organization, and also, what is appropriate for a different organization, cannot be properly regarded as having a unique environment, strategy, technology used, motivation of employees, organizational structure and managing style in every organization.

It is important to note that there can't be one, ideal method to run an organization, each company is unique and different from the others since each organization depends on its nature, application and culture and always has an original value system of its own. 
By maintaining a positive value coherence between the workers and their organisation, it is important to concentrate on employees' happiness by enhancing employment commitment and decreasing the stress of people at work. Organizations should thus make efforts to keep their workers and attempt to recruit new employees with excellent talents that will make the company more efficient and profitable.

\section{References:}

Bao, Y., Liao, S., Liao, J., Zhang, Y., Deng, C. \& Guo, Z. (2019). A study of the mechanism of the congruence of leader-follower power distance orientation on Employees' task performance. Front. Psychol. 10, 615.

Brandstatter, V., Job, V. \& Schulze, B. (2016). Motivational incongruence and well-being at the workplace: Person-Job Fit, Job burnout, and physical symptoms. Front Psychol. 7, 1153.

Edwards, J. \& Cable, D. (2009), The value of value congruence. Journal of applied psychology, 94 (3), 654-677.

Esposito, M. \& Williams, L. (2010). Moving Beyond Human and Organizational Incongruence. Grenoble ecole de management.

Mohr, S. \& Henson, W. (1996). Impact of employee gender and job congruency on customer satisfaction. Journal of consumer psychology, 5(2), 161-187.

Morgan, G. (1986). Images of organization. Beverly Hills CA: Sage.

Miles, R. E. \& Snow, C. (1978). Organization strategy, structure and process. New York: Mc-Grawhill.

Randolph, W. A. \& Gregory, G. (1984). The Congruence Perspective of Organization Design: A Conceptual Model and Multivariate Research Approach. The Academy of Management Review, 9 (1), 114-127.

Sabir, A. (2018). The congruence management -a diagnostic tool to identify problem areas in a company. Journal of political science and international relations, 1 (2), 34-38.

Spanjol, J. L. \& Tam, V. (2015). Employer-employee congruence in environmental values:an exploration of effects on job satisfaction and creativity. Journal of business ethics, $130(1), 117-130$.

Vveinhardt, J., Gulbovaite, E. \& Streimikiene, D. (2016), Values congruence from the executives' Viewpoint:Value-Based practices. Economics and sociology, 9 (2), 248-265.

Paper submitted

Paper accepted for publishing

Paper published online
29 April 2021

18 June 2021

31 July 2021 